\section{(2) OPEN ACCESS}

\title{
pathophysiology, diagnosis and practical management
}

\author{
Ayodele Sasegbon, ${ }^{1,2}$ Syed Shariq Hasan, ${ }^{2}$ Benjamin R Disney, ${ }^{3}$ \\ Dipesh Harshvadan Vasant (i) 1,2
}

\section{INTRODUCTION}

When translated into English, the Latin word ruminor means to chew over again. ${ }^{1}$ This word has been used to describe the behaviour of a class of herbivorous mammals who, due to the indigestibility of the foods they eat, require that food is regurgitated and rechewed before being reswallowed to aid its breakdown and subsequent digestion. ${ }^{2}{ }^{3}$ In certain herbivorous animals, ${ }^{3-5}$ rumination is, therefore, a normal, voluntary activity whereby gastric contents are brought up and rechewed as often as needed to optimise digestion. ${ }^{26}$ By contrast, rumination in humans, which was first described in $1618,{ }^{4}$ is pathological as omnivores have no need of chewing the cud and fermenting the resultant matter within the stomach.

In humans, rumination is thought to be an acquired behavioural disorder. ${ }^{7}$ It is often unconscious and can occur in both children and adults. ${ }^{8} 9$ Although individuals with learning difficulties ${ }^{10}$ or eating disorders ${ }^{11}$ can suffer from rumination syndrome, it can and indeed often occurs in otherwise healthy individuals. ${ }^{9}$

Depending on whether children or adults are being studied, the prevalence of rumination syndrome ranges from $0.1 \%$ to $4 \%{ }^{12} 13$ in children and $0.8 \%$ to $8 \%{ }^{14} 15$ in adults. In a recent Rome Foundation global epidemiological study, rumination syndrome was found to have an overall worldwide prevalence of $2.8 \%$ with women having a slightly higher prevalence $(3.1 \%)$ than men $(2.5 \%) .{ }^{16}$ A higher prevalence of rumination syndrome has been noted in those with eating disorders $(20 \%)^{17} 18$ and those with fibromyalgia $(8 \%) .^{14}$

\section{Key messages}

Rumination syndrome should be considered in any patient who presents with recurrent regurgitation without associated retching or significant nausea.

- Behavioural therapies including diaphragmatic breathing and biofeedback are effective treatments for rumination syndrome and have the largest evidence bases.

- Following treatment, most patients have large reductions in their frequency of regurgitation.

Despite rumination syndrome being a relatively common disorder of gut-brain interaction, evidence suggests it is not well understood, resulting in patients often having to visit a number of clinicians and undergo several investigations before a diagnosis is eventually reached. ${ }^{19}$ Consequently, a formal diagnosis can be delayed, leading to weight loss and malnutrition. ${ }^{19}$

This paper aims to set out the key diagnostic features of rumination syndrome, important differential diagnoses to consider, useful investigations to help dispel uncertainty and current evidencebased therapies.

\section{Clinical features}

Diagnostic criteria for rumination syndrome feature in the literature from three sources. First, the Rome IV diagnostic criteria for gastroduodenal disorders, ${ }^{20}$ the International Classification of Diseases ${ }^{21}$ or the Diagnostic and Statistical Manual for mental Disorders ${ }^{22}$ (table 1).

The key feature of rumination syndrome is the effortless regurgitation of recently ingested food or fluids which results in 
Table 1 Comparative Rome IV, ICD-11 and DSM-5 definitions of rumination syndrome ${ }^{20-22}$

\begin{tabular}{|c|c|c|c|}
\hline & Rome IV & ICD-11 & DSM-5 \\
\hline Description & $\begin{array}{l}\text { Regurgitation is followed by chewing and re-swallowing } \\
\text { food or spitting it out } \\
\text { No preceding retching } \\
\text { Supportive criteria } \\
\text { No nausea prior to regurgitation } \\
\text { Regurgitant contains recognisable food which may be } \\
\text { pleasant tasting } \\
\text { Regurgitation ceases when regurgitant becomes acidic }\end{array}$ & $\begin{array}{l}\text { Intentional and repeated regurgitation } \\
\text { of ingested food } \\
\text { This may be spat out or chewed and } \\
\text { re-swallowed }\end{array}$ & $\begin{array}{l}\text { Repeated regurgitation } \\
\text { of food which may be } \\
\text { re-swallowed or spat } \\
\text { out of the mouth }\end{array}$ \\
\hline Frequency of symptoms & - & Several times per week & - \\
\hline Duration of symptoms & $\begin{array}{l}\geq 3 \text { months prior to diagnosis with initial occurrence of } \\
\text { symptoms } \geq 6 \text { months prior to diagnosis }\end{array}$ & Several weeks & $\geq 1$ month \\
\hline
\end{tabular}

DSM-5, Diagnostic and Statistical Manual for mental Disorders; ICD-11, International Classification of Diseases.

patients either masticating and reswallowing the regurgitant or spitting it from their mouths. ${ }^{20}$ Importantly, this behaviour is not preceded by nausea or retching. Furthermore, it must have occurred on numerous occasions for weeks to months prior to diagnosis. ${ }^{20}$

Food and fluids can be repeatedly regurgitated for up to 2 hours after initial ingestion. ${ }^{23}$ In addition, the regurgitant is undigested and non-acidic, ${ }^{19}$ hence the reswallowed material often retains an inoffensive taste. Acidification of the regurgitant as digestion occurs often causes the regurgitation to stop. ${ }^{20}$

Invasive investigations are not usually required to establish the diagnosis of rumination syndrome. A comprehensive history to elicit the key clinical features (table 1) is sufficient in the majority of cases. Instead, focused investigations are often used where there is diagnostic uncertainty, significant weight loss or to exclude important differential diagnoses-which in the case of postprandial regurgitation are gastrooesophageal reflux disease (GORD) with regurgitation, achalasia and eating disorders.

\section{Pathophysiology}

Studies have shown that following the ingestion of food or fluids, patients with rumination syndrome frequently subconsciously and habitually contract their intercostal and anterior abdominal muscles. ${ }^{24}$ Contraction of the intercostal muscles results in costal expansion, while contraction of abdominal muscles including the rectus sheath and internal and external obliques increases intra-abdominal pressure. In conjunction with this, the lower oesophageal sphincter (LOS) relaxes. ${ }^{25-27}$ This is a reversal of the normal gastro-oesophageal pressure profile where at rest, intragastric pressure is normally low and LOS pressure is high. These resultant pressure changes result in gastric contents being propelled cranially into the oropharynx (figures 1 and 2). ${ }^{28}$

Rumination syndrome is an acquired behavioural disorder and, in some cases, a detailed history can reveal a particular priming episode of psychological stress or gastrointestinal (GI) upset (eg, gastroenteritis) which occurred prior to rumination being noticed. ${ }^{29} 30$ This event may be relatively minor and swiftly forgotten but it is theorised it prompts patients to tense their abdominal walls in order to relieve discomfort. ${ }^{7}$ This initial priming episode, later maintained and reinforced, leads to patients habitually tensing their abdomen postprandially. ${ }^{24}$ While rumination is almost always a primary condition, it is recognised that rumination can occasionally be a secondary response to gastro-oesophageal reflux episodes (secondary rumination), where the rumination behaviour is thought to be a conditioned, maladaptive response to oesophageal discomfort caused by GORD. ${ }^{26}$ Similarly, patients with established rumination often report postprandial

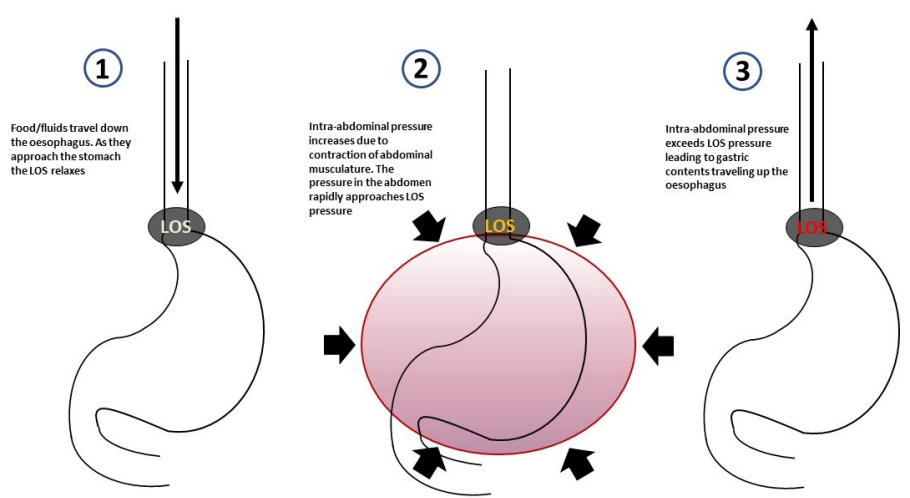

Figure 1 Illustration of the sequence of events that occur in rumination syndrome. LOS, lower oesophageal sphincter. 


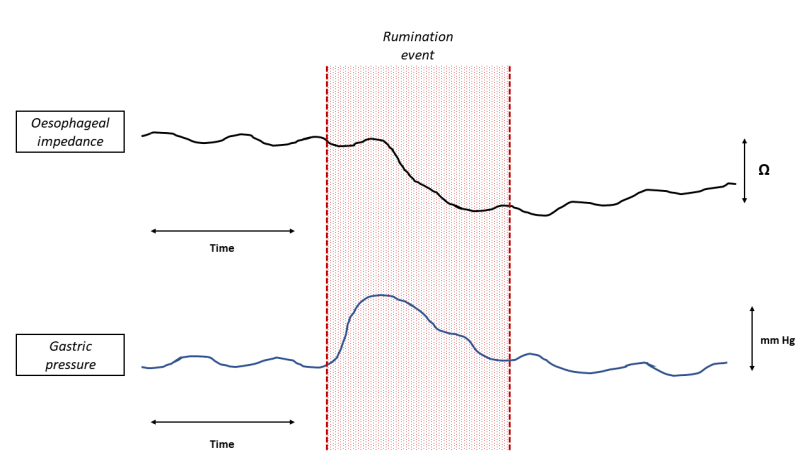

Figure 2 A simplified illustration of pressure and impedance traces during an episode of rumination. As can be seen, there is a postprandial increase in gastric pressure and a decrease in impedance (demonstrating cranial movement of gastric contents).

fullness or discomfort occurring before their episodes of regurgitation. ${ }^{7}$ Subsequent abdominal tensing and regurgitation may also be due to a subconscious, maladaptive method of discomfort reduction.

\section{Complications}

When severe, rumination syndrome can lead to malnutrition and dehydration which, in turn, can lead to electrolyte imbalances and the occurrence of refeeding syndrome when nutrition improves. ${ }^{31-33}$ Malnutrition and dehydration arise due to either a possible reduced desire to eat or drink so as to avoid episodes of regurgitation or spitting of food and fluids, reducing nutritional intake below what is required for good health. ${ }^{31}$

Additional complications in children and adults include failure to thrive, ${ }^{34}$ dental erosions, ${ }^{35}$ an increased likelihood of aspiration, ${ }^{23}$ halitosis ${ }^{36}{ }^{37}$ and stigma due to the rumination itself or its associated complications. $^{38}$

\section{Differential diagnoses}

While there is a long list of potential differentials for patients presenting with recurrent episodes of regurgitation, a few key conditions need to be excluded if, after a history is obtained, there remains a degree of uncertainty (table 2). GORD, achalasia, gastric outlet obstruction and gastroparesis can present with recurrent regurgitation although often with other symptoms including nausea and dysphagia. From a mental health standpoint, bulimia nervosa can mimic rumination syndrome, and an early psychiatric opinion should be sought if there is a suspicion of an eating disorder. ${ }^{17}$

\section{Investigations}

Usually, in the context of recurrent episodes of regurgitation, an oesophagogastroduodenoscopy (OGD) and/or a barium study will have been performed to exclude structural pathology in the upper GI tract. This would be mandatory prior to proceeding to oesophageal physiology testing as per national guidelines to
Table 2 Differential diagnoses and important clues for rumination syndrome

\begin{tabular}{|c|c|c|}
\hline Type of pathology & Clues & Diagnosis \\
\hline \multirow[t]{5}{*}{ Physical pathology } & $\begin{array}{l}\text { Occurring after meals } \\
\text { Nausea free } \\
\text { Effortless } \\
\text { Regurgitant not acidic } \\
\text { Recognisable undigested } \\
\text { food }\end{array}$ & $\begin{array}{l}\text { Rumination } \\
\text { syndrome }\end{array}$ \\
\hline & $\begin{array}{l}\text { Positional } \\
\text { Ameliorated by PPIs } \\
\text { - Acidic regurgitant }\end{array}$ & GORD \\
\hline & $\begin{array}{l}>\text { Nausea } \\
>\text { Pain }\end{array}$ & Achalasia \\
\hline & $\begin{array}{l}\text { Nausea } \\
\text { Diabetes(Often with } \\
\text { other complications, } \\
\text { neuropathy, etc) }\end{array}$ & Gastroparesis \\
\hline & $\begin{array}{l}\text { Nausea } \\
\text { Borborygmi } \\
\text { Succussion splash }\end{array}$ & $\begin{array}{l}\text { Gastric outlet } \\
\text { obstruction }\end{array}$ \\
\hline Mental illness & $\begin{array}{l}\text { Nausea } \\
\text { Self-induced } \\
\text { Body image-related } \\
\text { symptoms }\end{array}$ & Bulimia nervosa \\
\hline
\end{tabular}

GORD, gastro-oesophageal reflux disease; PPI, proton pump inhibitors.

exclude any contraindications to the passage of probes for motility studies. ${ }^{39}$

The gold standard investigation for rumination syndrome, in cases where a history is insufficient to make a firm diagnosis, is high-resolution oesophageal manometry (HROM) with concurrent impedance monitoring. The manometric aspect of the investigation enables visualisation of the abrupt rise in gastric pressure and subsequent postprandial relaxation of the LOS, while the concurrent impedance monitoring demonstrates the regurgitated material ${ }^{25}$ (figure $3 \mathrm{~A}$ ). Gastric pressures increase by $\geq 30 \mathrm{~mm} \mathrm{Hg}$ followed by cranial movement of gastric contents. ${ }^{26}$ HROM involves a manometry catheter, containing $>30$ pressure sensors interspersed at $1 \mathrm{~cm}$ intervals, ${ }^{39}$ being inserted transnasally before patients are asked to either lie supine (classically) or sit upright. The catheter is positioned so that its tip is roughly $5 \mathrm{~cm}$ below the LOS. Some advanced oesophageal high-resolution manometry systems have in-built combined oesophageal impedance capability which is ideal for the purpose of investigation for rumination. In the absence of a system with combined impedance/manometry, a second catheter in the opposite nostril for concurrent $\mathrm{pH} / \mathrm{imped}$ ance recording is often required. During a test for suspected rumination, patients are often instructed to consume a 'test meal' such as a cereal, and during the stationary manometry study monitoring is usually extended for up to 3 hours postprandially. During the test, oesophageal pressure and impedance traces can be visualised providing visual cues to demonstrate 


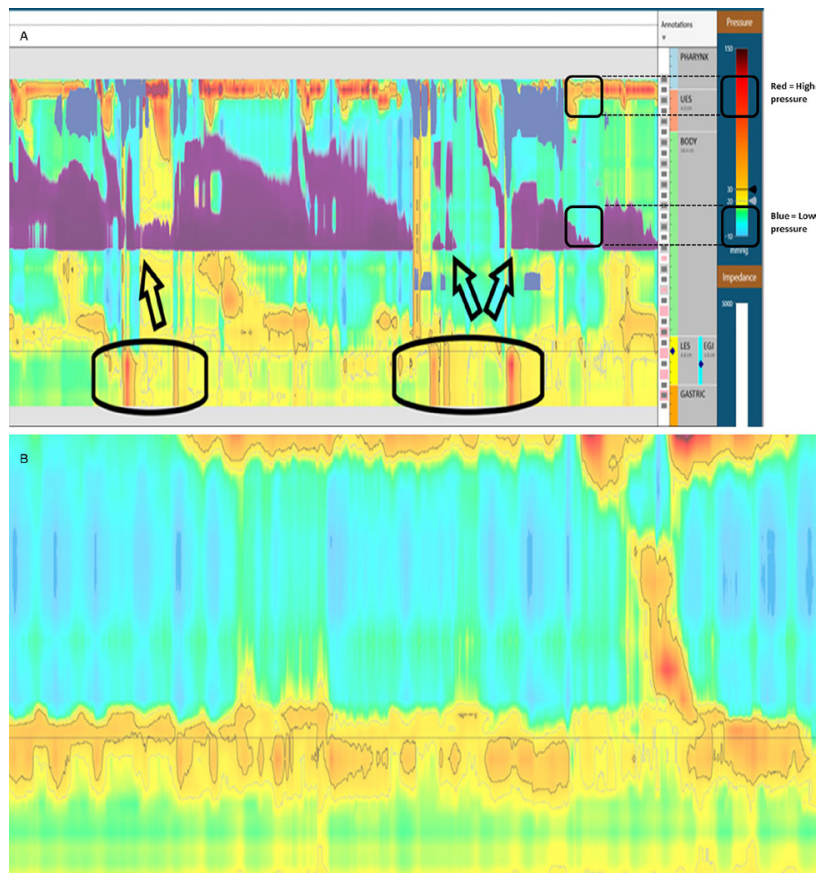

Figure 3 Pre and post behavioural treatment manometry findings in a patient with Rumination Syndrome. (A) High-resolution manometry showing postprandial abdominal contractions (circle) and proximal regurgitation (arrows). Red areas are areas of high pressure while blue areas are areas of low pressure. (B) Elimination of rumination-like behaviour during biofeedback and diaphragmatic breathing.

observed abnormalities to patients (figure $3 \mathrm{~A}$ ). This can help improve understanding and acceptance of the diagnosis. ${ }^{40}$ Episodes of rumination often occur sporadically, and can be influenced by an individual's social setting or level of distraction. As a result, longer studies with ambulatory 24-hour HROM, despite not being widely available, may have the potential to improve the diagnostic yield. ${ }^{41}$

\section{Management}

Explaining the diagnosis

Following a positive clinical diagnosis of rumination syndrome, one of the most crucial aspects of treatment is an effective doctor-patient interaction. This should include a detailed explanation to educate the patient on the nature and pathophysiology of the condition with reassurance. A sympathetic approach, explaining that the regurgitation is caused by an involuntary habit, leading to subconscious tension of the abdominal muscles is often extremely beneficial and therapeutic. ${ }^{42}$ These explanations can be reinforced by the provision of a patient information leaflet recently developed by Guts-UK (https://gutscharity.org.uk/advice-and-information/conditions/rumination-syndrome/).

Armed with the knowledge of why they regurgitate, and reassurance that a sinister cause has been confidently excluded, many patients may not need any further intervention. However, should they require further treatment, the treatment options, summarised in figure 4 , include behavioural and to a lesser extent

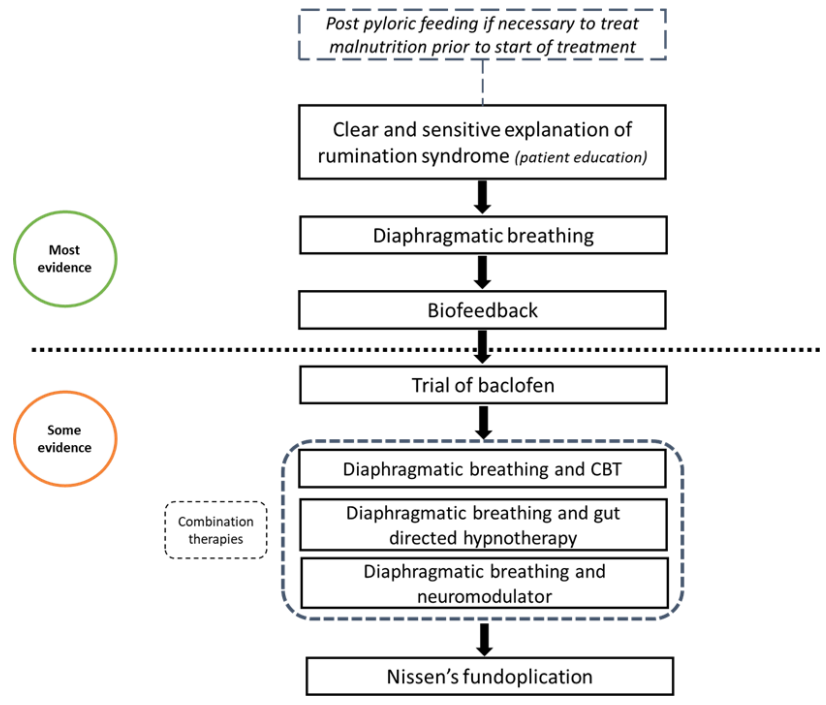

Figure 4 Rumination syndrome management flow chart. CBT, cognitive-behavioural therapy.

medical approaches which are often used in combination in refractory cases.

Nutritional considerations

Prior to receiving a formal diagnosis and treatment plan, patients with suspected rumination syndrome can be at risk of malnutrition. A comprehensive nutritional assessment is required to assess for features of malnutrition, and some patients with features of malnutrition may need consideration for a period of nutritional support with nasojejunal/post-pyloric feeding prior to the commencement of definitive rumination treatment. While a detailed review of nutritional assessment and management is beyond the scope of this article, this has been covered in a recent comprehensive review on the indications and role of post-pyloric feeding in this context. $^{43}$

\section{Behavioural therapy}

Behavioural interventions have the greatest evidence base for the treatment of rumination syndrome. The two interventions most often used are diaphragmatic breathing and biofeedback.

Diaphragmatic breathing can be taught at the bedside by clinicians, nurse specialists, speech and language therapists or behavioural therapists. It involves instructing patients to breathe by expanding and contracting their abdomen, as opposed to the normal pattern of chest wall movements with respiration. ${ }^{44}$ Essentially, patients are asked to place one hand on the anterior aspect of their chests and one hand on their abdomen. They are then asked to breathe in such a way that their abdominal hand rises and falls while their chest hand remains still. This technique is thought to work by disrupting the postprandial abdominal contractions which cause regurgitation. ${ }^{28}$ Diaphragmatic breathing has been shown to significantly reduce the frequency of regurgitation, increase 
the pressure at the oesophagogastric junction and reduce intragastric pressure. ${ }^{28}$ Furthermore, it is can be easily learnt by participants, taking roughly $5 \mathrm{~min} .{ }^{28}$ When patients are taught to breathe in this manner, they are initially asked to lie flat with their knees bent so as to relax their abdomen. Over time, as this type of breathing becomes easier to perform, patients can be encouraged to perform diaphragmatic breathing while seated upright. Patients should be advised to practise diaphragmatic breathing for 5-10 min whenever regurgitation occurs. This can be done during or following each meal. However, should they experience any regurgitation between meals, they are advised to perform additional diaphragmatic breathing. The aim is to promote this type of breathing to become the normal type of breathing practised during the postprandial period in order to suppress rumination behaviours. An educational video demonstrating diaphragmatic breathing has been produced by the authors to compliment this article and can be accessed online via weblink (https://youtu.be/h46ZsxfpSOU).

When the response to diaphragmatic breathing is incomplete, more advanced behavioural therapy with biofeedback may be an effective tool for rumination syndrome. The principles of biofeedback for rumination are to promote behavioural modification and improve the efficacy of diaphragmatic breathing by visually demonstrating the physiological abnormalities to the patient and how they can be corrected in real time (figure 3). Formal biofeedback using this approach either with electromyography or HROM can be effective in teaching patients how to relax their abdominal wall musculature after eating using visual cues resulting in a significant reduction in the frequency of regurgitation (figure 3B). ${ }^{245}$ While the availability of formal biofeedback programmes for this condition in the UK is limited, a brief intervention can readily be delivered by any clinician able to teach diaphragmatic breathing during a diagnostic concurrent HROM/impedance study in patients with positive manometry findings for rumination. In the authors' experience, this type of brief intervention at the end of a diagnostic test can be very beneficial in helping the patient optimise their diaphragmatic breathing technique ${ }^{46}$ and improving symptom control.

Recent evidence suggests that diaphragmatic breathing and biofeedback are not only beneficial for treating primary rumination, ${ }^{26}$ but may also be effective in treating secondary rumination associated with acid reflux, either with or without antacid therapy, due to the positive effects of diaphragmatic breathing on reducing acid reflux events and acid exposure times. ${ }^{2647}$

In a similar behavioural vein, there is some evidence from paediatric case reports that chewing gum after meals reduces the frequency of regurgitation. ${ }^{48}$ This is thought to work by distracting patients. Additionally, a recent study by Murray et al used cognitive-behavioural therapy (CBT) to supplement diaphragmatic breathing. Following dual behavioural therapy, participants had greater reductions in regurgitation than following diaphragmatic breathing alone. ${ }^{49}$ Where available, gut-specific behavioural techniques such as CBT, or gut-focused hypnotherapy, a technique that often incorporates diaphragmatic breathing, may therefore have an adjunctive role, ${ }^{50}$ and their additional benefit should be investigated in future studies.

\section{Pharmacological therapy}

There are very few studies on effective medical therapy for rumination syndrome. Baclofen may however be a reasonable option as second-line management option following behavioural approaches. Baclofen works by increasing the resting tone of the LOS thereby reducing the ease of reflux of gastric contents. ${ }^{51}$ Unfortunately, it is known to cause various side effects, which commonly include drowsiness, dizziness and headaches. ${ }^{52}$ Despite these side effects, studies using baclofen to treat GORD have shown that it is well tolerated when taken at low doses. ${ }^{53}$ Two small studies have shown that baclofen can be used to treat rumination syndrome with promising results. The first was by Blondeau et al in 2012 in a sample of 12 patients, ${ }^{54}$ where $10 \mathrm{mg}$ of baclofen administered three times per day was shown to increase lower oesophageal sphincter tone and reduce episodes of regurgitation. These findings were confirmed in 2018 by Pauwels et $a l$ in a group of 20 patients. ${ }^{55}$

Furthermore, a study by Robles et al combining diaphragmatic breathing with a tricyclic antidepressant as a gut-brain neuromodulator showed large reductions in postprandial regurgitation, ${ }^{56}$ suggesting that the addition of a neuromodulator may augment the effects of behavioural therapy.

\section{Surgical intervention}

Limited evidence from case series ${ }^{23}$ suggests that in refractory cases, rumination syndrome can be treated with Nissen's fundoplication in order to enhance the resting pressure of the LOS and to partially negate the intragastric propulsive force provided by contraction of anterior wall musculature by reducing concurrent LOS relaxation. Due to the lack of high-quality evidence, the role of surgery remains unclear, and should only be considered on a case-by-case basis, when there is a firm diagnosis of severe rumination, refractory to all the recommended behavioural and medical options, and with ongoing inadequate oral intake. There may however be a stronger case for anti-reflux surgery in patients where secondary rumination events have been shown to be triggered by acid reflux events on impedance/manometry traces without response to antireflux medications. In the rare setting when surgery is considered for severe, refractory, primary rumination, the diagnosis should ideally be supported by positive impedance and manometry studies. In summary, 
further research is required to firmly establish the role of invasive surgery in this acquired behavioural condition.

\section{Rumination clinical scenarios} Scenario 1

A young patient with no significant medical history was referred with reflux symptoms for a second opinion. The patient had been investigated elsewhere with a normal upper GI endoscopy. On further questioning, the patient reported a long history of postprandial effortless regurgitation. There was no associated nausea, vomiting, dysphagia or weight loss. The regurgitated material was often reswallowed but on occasion spat out.

A diagnosis of rumination syndrome was discussed and explained to the patient, who agreed with the diagnosis and was reassured by this. A trial of diaphragmatic breathing during mealtimes and in the postprandial period was advised which resulted in significant symptom improvement.

This case highlights that in some cases of rumination syndrome, explanation of the condition, along with reassurance, is all that is required.

\section{Scenario 2}

A patient with a history of vomiting shortly after eating was referred to gastroenterology clinic. On detailed questioning, the patient reported almost immediate regurgitation of food and medications shortly after swallowing. There was no nausea, vomiting or weight loss. A small hiatus hernia was noted on OGD.

HROM with concurrent impedance demonstrated evidence of intragastric pressurisation throughout the study with evidence of retrograde bolus flow regurgitation. The findings were consistent with rumination syndrome. Diaphragmatic breathing was advised but had limited effect. Therefore, the patient was referred for HROMdirected biofeedback with diaphragmatic breathing which successfully eliminated the rumination-like behaviour.

\section{CONCLUSION}

Rumination syndrome is a poorly recognised, infrequently diagnosed, yet easily manageable disorder of gut-brain interaction. Greater awareness among medical professionals will ensure prompt diagnosis, prevent malnutrition and reduce inappropriate referrals for psychiatric assessments or invasive investigations.

Twitter Syed Shariq Hasan @hasan20187, Benjamin R Disney @DisneyBen and Dipesh Harshvadan Vasant @DipeshVasant

Contributors AS drafted the manuscript and performed literature review. BRD reviewed and helped write the manuscript and provided original figures. SSH reviewed the paper, contributed to the section of behavioural therapies and helped produce supplementary educational material on diaphragmatic breathing. DHV conceived the paper, searched the literature and helped write and review the paper.

Funding The authors have not declared a specific grant for this research from any funding agency in the public, commercial or not-for-profit sectors.
Competing interests None declared.

Patient consent for publication Not required.

Ethics approval This study does not involve human participants.

Provenance and peer review Not commissioned; externally peer reviewed.

Open access This is an open access article distributed in accordance with the Creative Commons Attribution Non Commercial (CC BY-NC 4.0) license, which permits others to distribute, remix, adapt, build upon this work noncommercially, and license their derivative works on different terms, provided the original work is properly cited, appropriate credit is given, any changes made indicated, and the use is noncommercial. See: http://creativecommons.org/licenses/by-nc/4. $0 /$.

\section{ORCID iD}

Dipesh Harshvadan Vasant http://orcid.org/0000-0002-23290616

\section{REFERENCES}

1 Merriam-Webster, 2021. Ruminate. Available: https://www. merriam-webster.com/dictionary/ruminate\#learn-more2021

2 RUCKEBUSCH M. [Central control of rumination]. Ann Nutr Aliment 1961;15:261-3 https://pubmed.ncbi.nlm.nih.gov/ 14494979/

3 Beauchemin KA. Ingestion and mastication of feed by dairy cattle. Veterinary Clinics of North America: Food Animal Practice 1991;7:439-63.

4 Engelhardt Wvon, Haarmeyer P, Kaske M, et al. Chewing activities and oesophageal motility during feed intake, rumination and eructation in camels. J Comp Physiol B 2006;176:117-24.

5 FranÇoise domingue BM, Dellow DW, Barry TN. The efficiency of chewing during eating and ruminating in goats and sheep. Br J Nutr 1991;65:355-63.

6 WINSHIP DH, ZBORALSKE FF, WEBER WN, et al. Esophagus in RUMINATION. Am J Physiol 1964;207:118994.

7 Murray HB, Juarascio AS, Di Lorenzo C, et al. Diagnosis and treatment of Rumination syndrome: a critical review. $A m J$ Gastroenterol 2019;114:562-78.

8 Rajindrajith S, Devanarayana NM, Crispus Perera BJ. Rumination syndrome in children and adolescents: a school survey assessing prevalence and symptomatology. BMC Gastroenterol 2012;12:163.

9 Lee H, Rhee P-L, Park E-H, et al. Clinical outcome of rumination syndrome in adults without psychiatric illness: a prospective study. J Gastroenterol Hepatol 2007;22:1741-7.

10 Rogers B, Stratton P, Victor J, et al. Chronic regurgitation among persons with mental retardation: a need for combined medical and interdisciplinary strategies. Am J Ment Retard 1992;96:522-7.

11 Wang X, Luscombe GM, Boyd C, et al. Functional gastrointestinal disorders in eating disorder patients: altered distribution and predictors using Rome III compared to Rome II criteria. WJG 2014;20:16293-9.

12 Devanarayana NM, Adhikari C, Pannala W, et al. Prevalence of functional gastrointestinal diseases in a cohort of Sri Lankan adolescents: comparison between Rome II and Rome III criteria. J Trop Pediatr 2011;57:34-9.

13 Sagawa T, Okamura S, Kakizaki S, et al. Functional gastrointestinal disorders in adolescents and quality of school life. J Gastroenterol Hepatol 2013;28:285-90.

14 Almansa C, Rey E, Sánchez RG, et al. Prevalence of functional gastrointestinal disorders in patients with fibromyalgia and the role of psychologic distress. Clin Gastroenterol Hepatol $2009 ; 7: 438-45$. 
15 López-Colombo A, Morgan D, Bravo-González D, et al. The epidemiology of functional gastrointestinal disorders in Mexico: a population-based study. Gastroenterol Res Pract 2012;2012:1-8.

16 Sperber AD, Bangdiwala SI, Drossman DA, et al. Worldwide prevalence and burden of functional gastrointestinal disorders, results of Rome Foundation global study. Gastroenterology 2021;160:99-114.

17 Fairburn CG, Cooper PJ. Rumination in Bulimia nervosa. BMJ 1984;288:826-7.

18 Fairburn CG, Cooper PJ. The clinical features of Bulimia nervosa. Br J Psychiatry 1984;144:238-46.

19 O'Brien MD, Bruce BK, Camilleri M. The rumination syndrome: clinical features rather than manometric diagnosis. Gastroenterology 1995;108:1024-9.

20 Foundation R. Rome IV criteria the Rome Foundation. 4th edn, 2016. https://theromefoundation.org/rome-iv/rome-iv-criteria/

21 WHO. Rumination-regurgitation disorder. 11th edn, 2021. https://icd.who.int/browse11/1-m/en\#http\%3a\%2f\%2fid.who. int $\% 2$ ficd $\% 2$ fentity $\% 2$ f 1205760590

22 American-Psychiatric-Association. Diagnostic and statistical manual of mental health disorders. 5th edn, 2013.

23 Oelschlager Bet al. Effective treatment of rumination with Nissen fundoplication. J Gastrointest Surg 2002;6:638-44.

24 Barba E, Burri E, Accarino A, et al. Biofeedback-guided control of abdominothoracic muscular activity reduces regurgitation episodes in patients with rumination. Clin Gastroenterol Hepatol 2015;13:100-6.

25 Singendonk MMJ, Oors JM, Bredenoord AJ, et al. Objectively diagnosing rumination syndrome in children using esophageal pH-impedance and manometry. Neurogastroenterol Motil 2017;29:e12996.

26 Kessing BF, Bredenoord AJ, Smout AJPM. Objective manometric criteria for the rumination syndrome. Am J Gastroenterol 2014;109:52-9.

27 Smout AJ, Breumelhof R. Voluntary induction of transient lower esophageal sphincter relaxations in an adult patient with the rumination syndrome. Am J Gastroenterol 1990;85:16215.

28 Halland M, Parthasarathy G, Bharucha AE, et al. Diaphragmatic breathing for rumination syndrome: efficacy and mechanisms of action. Neurogastroenterol. Motil. 2016;28:384-91.

29 Fernandez S, Aspirot A, Kerzner B, et al. Do some adolescents with rumination syndrome have "supragastric vomiting"? J Pediatr Gastroenterol Nutr 2010;50:103-5.

30 Mousa HM, Montgomery M, Alioto A. Adolescent Rumination syndrome. Curr Gastroenterol Rep 2014;16:398.

31 Green AD, Alioto A, Mousa $\mathrm{H}$, et al. Severe pediatric rumination syndrome: successful interdisciplinary inpatient management. J Pediatr Gastroenterol Nutr 2011;52:414-8.

32 Disney B, Trudgill N. Managing a patient with rumination. Frontline Gastroenterol 2013;4:232-6.

33 Friedli N, Stanga Z, Sobotka L, et al. Revisiting the refeeding syndrome: results of a systematic review. Nutrition 2017;35:151-60.

34 Clark D. Rumination in a failure-to-thrive infant. Matern Child Nurs J 1975;4:9-22.

35 Monagas J, Ritwik P, Kolomensky A, et al. Rumination syndrome and dental erosions in children. J Pediatr Gastroenterol Nutr 2017;64:930-2.

36 Struch F, Schwahn C, Wallaschofski H, et al. Self-Reported halitosis and gastro-esophageal reflux disease in the general population. J Gen Intern Med 2008;23:260-6.

37 Moshkowitz M, Horowitz N, Leshno M, et al. Halitosis and gastroesophageal reflux disease: a possible association. Oral Dis 2007;13:581-5.
38 Mento C, Lombardo C, Milazzo M, et al. Adolescence, adulthood and self-perceived halitosis: a role of psychological factors. Medicina 2021;57:614.

39 Trudgill NJ, Sifrim D, Sweis R, et al. British Society of gastroenterology guidelines for oesophageal manometry and oesophageal reflux monitoring. Gut 2019;68:1731-50.

40 Halland M, Pandolfino J, Barba E. Diagnosis and treatment of Rumination syndrome. Clin Gastroenterol Hepatol 2018;16:1549-55.

41 Kessing BF, Govaert F, Masclee AAM, et al. Impedance measurements and high-resolution manometry help to better define rumination episodes. Scand J Gastroenterol 2011;46:1310-5.

42 Levine DF, Wingate DL, Pfeffer JM, et al. Habitual rumination: a benign disorder. Br Med J 1983;287:255-6.

43 Paine P, McMahon M, Farrer K, et al. Jejunal feeding: when is it the right thing to do? Frontline Gastroenterol 2020;11:397403.

44 Chitkara DK, Van Tilburg M, Whitehead WE, et al. Teaching diaphragmatic breathing for rumination syndrome. Am J Gastroenterol 2006;101:2449-52.

45 Barba E, Accarino A, Soldevilla A, et al. Randomized, placebo-controlled trial of biofeedback for the treatment of Rumination. Am J Gastroenterol 2016;111:1007-13.

46 Vasant D, Disney B. How to recognise and manage rumination syndrome, 2020. Bsg. Available: www.bsg.org.uk/clinicalarticles-list/how-to-recognise-and-manage-ruminationsyndrome

47 Halland M, Bharucha AE, Crowell MD, et al. Effects of diaphragmatic breathing on the pathophysiology and treatment of upright gastroesophageal reflux: a randomized controlled trial. Am J Gastroenterol 2021;116:86-94.

48 Weakley MM, Petti TA, Karwisch G. Case study: chewing gum treatment of rumination in an adolescent with an eating disorder. J Am Acad Child Adolesc Psychiatry 1997;36:11247.

49 Murray HB, Zhang F, Call CC, et al. Comprehensive cognitive-behavioral interventions augment diaphragmatic breathing for Rumination syndrome: a proof-of-concept trial. Dig Dis Sci 2021;66:3461-9.

50 Vasant DH, Whorwell PJ. Gut-focused hypnotherapy for functional gastrointestinal disorders: Evidence-base, practical aspects, and the Manchester protocol. Neurogastroenterology o Motility 2019;31:e13573.

51 grossi 1, spezzaferro m, sacco lf, et al. Effect of baclofen on oesophageal motility and transient lower oesophageal sphincter relaxations in GORD patients: a 48-h manometric study. Neurogastroenterol Motil 2008;20:760-6.

52 NICE. Baclofen: National Institute for health and care excellence, 2021. Available: https://www.nice.org.uk/

53 Cossentino MJ, Mann K, Armbruster SP, et al. Randomised clinical trial: the effect of baclofen in patients with gastrooesophageal reflux--a randomised prospective study. Aliment Pharmacol Ther 2012;35:n/a-44.

54 Blondeau K, Boecxstaens V, Rommel N, et al. Baclofen improves symptoms and reduces postprandial flow events in patients with rumination and supragastric belching. Clinical Gastroenterology and Hepatology 2012;10:379-84.

55 Pauwels A, Broers C, Van Houtte B, et al. A randomized double-blind, placebo-controlled, cross-over study using baclofen in the treatment of Rumination syndrome. Am J Gastroenterol 2018;113:97-104.

56 Robles A, Romero YA, Tatro E, et al. Outcomes of treating Rumination syndrome with a tricyclic antidepressant and diaphragmatic breathing. Am J Med Sci 2020;360:42-9. 